\title{
Pengetahuan dan Sikap Tenaga Kesehatan Terhadap Pengelolaan Limbah Medis Padat pada Salah Satu Rumah Sakit di Kota Bandung
}

\author{
Annisa Fitri Maharani ${ }^{1}$, Irvan Afriandi ${ }^{2}$, Titing Nurhayati ${ }^{3}$ \\ ${ }^{1}$ Fakultas Kedokteran, Universitas Padjadjaran, \\ ${ }^{2}$ Departemen Ilmu Kesehatan Masyrakat, Fakultas Kedokteran Universitas Padjadjaran \\ ${ }^{3}$ Departemen Fisiologi, Fakultas Kedokteran Universitas Padjadjaran
}

\begin{abstract}
Abstrak
Limbah medis padat memiliki risiko terhadap kesehatan seperti penularan penyakit. Tenaga kesehatan di rumah sakit rentan terhadap risiko pengelolaan limbah medis. Penelitian ini bertujuan untuk mengetahui gambaran dan hubungan pengetahuan dan sikap tenaga kesehatan terhadap pengelolaan limbah medis padat. Penelitian ini merupakan observasional komparatif yang dilakukan pada tenaga kesehatan di salah satu RSKIA Kota Bandung pada bulan Agustus 2016. Metode penelitian adalah cross-sectional dengan metode sampling propotional random sampling. Jumlah sampel sebanyak 159 responden. Terdapat $56,6 \%$ tenaga kesehatan yang memiliki pengetahuan baik, 25,8\% sedang dan 17,6\% memiliki pengetahuan kurang. Diketahui pula 82,4\% tenaga kesehatan memiliki sikap yang baik dan $17,6 \%$ sikap kurang baik terhadap pengelolaan limbah medis padat. Hubungan antara pengetahuan pengelolaan limbah medis padat dengan tenaga kesehatan dokter dan non dokter $(p<0,001)$ sedangkan sikap pengelolaan limbah medis padat tidak memiliki hubungan dengan tenaga kesehatan dokter dan non dokter $(\mathrm{p}=$ $0,300)$. Dokter memiliki pengetahuan dan sikap terhadap pengelolaan limbah medis padat lebih baik dibandingkan non dokter. Terdapat hubungan antara pengetahuan pengelolaan limbah medis padat dengan tenaga kesehatan tetapi tidak terdapat hubungan antara sikap terhadap pengelolaan limbah medis padat dengan tenaga kesehatan
\end{abstract}

Kata Kunci : Limbah medis padat, Pengelolaan, Pengetahuan, Sikap

\section{Knowledge and Attitudes of Health Workers for Medical Solid Waste Management at One Hospital in Bandung}

\begin{abstract}
Solid biomedical waste has risks towards health such as disease transmission and accidents. Health workers in hospitals are vulnerable towards the risk of biomedical waste management. This research aims to find out the overview and relationship of knowledge and attitude of health workers towards solid biomedical waste management. This observational comparative research was conducted on health workers in Bandung Women and Children's Hospital in August 2016. Cross-sectional method was used with proportional random sampling. The samples amounted to 159 respondents. This research found out that 56.6\% of the health workers showed satisfactory knowledge, 25,8\% moderate and 17,6\% showed unsatisfactory knowledge. $82.4 \%$ of the health workers harbored positive attitude while the $17.6 \%$ of the health workers harbored negative attitude towards the management of solid biomedical waste. Other than that there's a relationship between the knowledge of solid biomedical waste management with physician and non-physician health workers $(p<0,001)$, while the attitude of solid biomedical waste management didn't have a relationship with physician and non-physician health workers $(p=0,300)$. Physicians had better knowledge and attitude towards solid biomedical waste management compared to non-physicians. And there's a relationship between the knowledge of solid biomedical waste management with health workers but there's no relationship between attitude towards solid biomedical waste management with health workers.
\end{abstract}

Keywords : Attitude, Management, Knowledge, Solid biomedical waste

Korespondensi:

Annisa Fitri Maharani

Fakultas Kedokteran, Universitas Padjadjaran

Jl. Raya Bandung-Sumedang km 21 Jatinangor

Mobile : 082115605355

Email : annisafmica@gmail.com 


\section{Pendahuluan}

Rumah Sakit merupakan salah satu tempat penghasil limbah. Limbah yang dihasilkan yaitu limbah domestik dan limbah medis. Limbah medis adalah limbah yang dihasilkan dari suatu layanan kesehatan, termasuk dalam semua hasil buangan yang berasal dari instalasi kesehatan, fasilitas penelitian dan laboratorium yang berhubungan dengan prosedur medis. ${ }^{1}$ Limbah medis di klasifikasikan menjadi beberapa klasifikasi, salah satunya yaitu limbah medis padat. Limbah medis padat adalah limbah yang dihasilkan dari suatu layanan kesehatan dalam bentuk padat, yang terdiri dari limbah infeksius, limbah patologi, limbah benda tajam, limbah farmasi, limbah sitoksis, limbah kimiawi, limbah radioaktif, limbah kontainer bertekanan dan limbah dengan kandungan logam berat yang tinggi. ${ }^{2}$

Pengelolaan limbah medis rumah sakit sangatlah penting karena limbah medis memiliki berbagai risiko terhadap kesehatan bagi siapa saja, termasuk karyawan rumah sakit, pasien dan masyarakat. ${ }^{3}$ Semua orang yang terpajan limbah berbahaya dan yang berada dalam lingkungan penghasil limbah berbahaya dari fasilitas kesehatan, kemungkinan besar berisiko untuk mendapatkan dampak dari limbah medis berbahaya tersebut. Tetapi mereka yang berada di luar fasilitas kesehatan serta memiliki pekerjaan dalam mengelola limbah semacam itu pun memiliki risiko dari dampak limbah medis, akibat kecerobohan dalam sistem manajemen limbahnya. ${ }^{1}$

Tenaga kesehatan di rumah sakit rentan terhadap risiko yang berhubungan dengan pengelolaan limbah medis. Risiko pekerjaan tenaga kesehatan seperti tertusuknya jarum bekas/tidak steril menjadi faktor risiko kedua tertinggi terhadap penularan penyakit hepatitis B pada tenaga kesehatan. ${ }^{4}$

Pengetahuan dan sikap tenaga kesehatan terhadap pengelolaan limbah medis sangatlah penting, terlebih lagi hubungan antara pengetahuan dan sikap pengelolaan limbah medis terhadap tenaga kesehatan. Hasil penelitian di Dhaka Bangladesh menunjukan bahwa hampir sepertiga dokter dan perawat, juga dua pertiga staf teknologi dan kebersihan memiliki pengetahuan yang tidak memadai. Selain itu diketahui pula bahwa hasil survei mengatakan $44 \%$ dari dokter dan $56 \%$ dari staf kebersihan ternyata memiliki kebiasaan membuang limbah medis tidak semestinya. ${ }^{5}$ Demikian telah dilakukan penelitian pada suatu Puskesmas di Kabupaten Jember mengenai hubungan antara tingkat pengetahuan dan sikap petugas dengan perilaku dalam tahapan pengelolaan sampah medis. Terdapat hubungan antara tingkat pengetahuan dengan perilaku petugas dalam pengelolaan sampah medis $(\mathrm{p}=$ 0,003 ) dan adanya hubungan pula antara sikap petugas dengan perilaku pengelolaan limbah medis padat $(\mathrm{p}=0,000) .{ }^{6}$ Pada penelitian lain yang dilakukan di Yogyakarta menyatakan bahwa terdapat hubungan yang kuat antara tingkat pengetahuan dengan perilaku perawat dalam pembuangan sampah medis $(p=0,002)$ dan terdapat hubungan antara sikap dengan perilaku perawat dalam pembuangan sampah medis di rumah sakit PKU Muhammadiyah Yogyakarta ( $\mathrm{p}$ $=0,000)^{7}$

Tenaga kesehatan memiliki peran penting dalam pengelolaan limbah medis karena mereka menjadi penghasil limbah medis dari kegiatan layanan kesehatan dan juga yang berkontak langsung dengan limbah medis. Oleh karenanya para tenaga kesehatan perlu untuk memiliki pengetahuan juga sikap yang baik terhadap pengelolaan limbah medis. Namun demikian, sejauh ini belum banyak diketahui seberapa jauh para tenaga kesehatan di fasilitas kesehatan memiliki pengetahuan dan sikap terhadap pengelolaan limbah medis padat dan juga belum banyak dijelaskan hubungan diantaranya

Berdasarkan penelitian tersebut, maka penelitian ini bertujuan untuk mengetahui gambaran dan hubungan antara pengetahuan dan sikap pengelolaan limbah medis padat dengan tenaga kesehatan yang terbagi atas dokter dan non dokter.

\section{Metode}

Penelitian ini adalah penelitian observasional komparatif dengan metode penelitian crosssectional yang dilakukan pada bulan Agustus hingga November 2016 di Rumah Sakit Khusus Ibu dan Anak Kota Bandung. Persetujuan etik penelitian diperoleh dari Komisi Etik Penelitian Kesehatan Fakultas Kedokteran Universitas Padjadjaran Bandung berdasarkan etchical clearance No: 514/UN6.C1.3.2/KEPK/PN/2016. Jumlah sampel yang diperoleh sebanyak 159 responden dari hasil perhitungan rumus Cochran dan rumus Finite. Dengan nilai $\mathrm{Z}$ adalah 1,96 dari interval kepercayaan $95 \%$, nilai $\mathrm{P}$ adalah 0,5 dimaksudkan untuk memperoleh besar sampel yang maksimaldan nilai e yang ditetapkan oleh peneliti adalah 5\%. Subjek penelitian yang menjadi responden adalah dokter, perawat, bidan, analis dan farmasi yang memenuhi kriteria inklusi yaitu tenaga kesehatan yang bekerja pada Rumah Sakit Khusus Ibu dan Anak kota Bandung, sebagai penghasil atau berkontak dengan limbah medis padat dan bersedia menjadi responden dengan 
menandatangani lembar persetujuan. Kriteria eksklusi yaitu tenaga kesehatan yang mengisi kuesioner secara tidak lengkap, sudah menjadi responden pada uji validasi kuesioner dan sedang mengambil cuti. Dari jumlah populasi dalam peneliatian ini adalah 268 terdapat 46 responden yang dieksklusi sehingga tersisa 222 orang yang masuk kriteria inklusi dan dapat menjadi responden dalam penelitian ini diantaranya yaitu 27 dokter, 85 perawat, 78 bidan, 18 farmasi dan 14 analis. Pengambilan sampel dilakukan dengan propotional random sampling, sehingga diperoleh 19 dokter, 61 perawat, 56 bidan, 13 farmasi dan 10 analis. Akhirnya terdapat 159 responden yang memenuhi minimal sampel yang telah di tetapkan dan telah mengisi kuesioner dengan tepat.

Data dikumpulkan melalui wawancara terstruktur dengan menggunakan kuesioner. Uji coba kuesioner dilakukan dengan cara membagikannya kepada 30 tenaga kesehatan di Rumah Sakit Khusus Ibu dan Anak Kota Bandung dan pada akhirnya kuesioner yang sudah tervalidasi akan dibagikan untuk peneliatian kepada 159 petugas tenaga kesehatan di Rumah Sakit Khusus Ibu dan Anak Kota Bandung yang mana responden untuk validasi kuesioner berbeda dengan responden untuk penelitian. Kuesioner berisi pertanyaan untuk menilai pengetahuan dan sikap tenaga kesehatan mengenai pengelolaan limbah medis padat. Tingkat pengetahuan diukur menggunakan metode benar salah sedangkan untuk mengukur sikap menggunakan metode Skala Likert dari penilaian sangat setuju, setuju, tidak berpendapat, tidak setuju, hingga sangat tidak setuju.

Kuesioner tersebut telah diuji reliabilitas yang dilakukan sendiri oleh peneliti. Hasil Cronbach's Alpha untuk kuesioner dengan variabel pengetahuan adalah 0.666 sedangkan untuk hasil Cronbach's Alpha kuesioner dengan variabel sikap adalah 0.781 dan karena uji kuesioner dilakukan kepada 30 responden maka diketahui nilai $r=0.3610$ dengan hasil $r$ tiap pertanyaan tercantum pada lampiran.

Data yang telah dikumpukan kemudian dianalisis menggunakan microsoft excel dan SPSS, lalu dikelompokan ke dalam setiap kategori berdasarkan dokter dan non dokter dan dilihat persentase kebenaran dari jawaban responden. Pengetahuan kategori dibagi menjadi 3: baik $(>85 \%)$, sedang $(71 \%-85 \%)$ dan kurang $(\leq 70 \%)$. Kategori sikap dibagi berdasarkan 2 kelompok: baik $(>70 \%)$ dan kurang baik $(\leq 70 \%)$.

\section{Hasil}

Jumlah responden yang didapatkan pada penelitian ini adalah 159 tenaga kesehatan yang terdiri dari 19 dokter dan 140 non dokter. Terdapat 140 non dokter diantaranya 61 perawat, 56 bidan, 13 farmasi dan 10 analis.

Berdasarkan tabel 1 menunjukan bahwa mayoritas responden berjenis kelamin perempuan yaitu $86,8 \%$ dan yang berjenis kelamin laki-laki yaitu $13,2 \%$. Didapatkan pula bahwa responden penelitian ini lebih banyak berasal dari perawat $(38,4 \%)$ karena tenaga kesehatan yang ada di Rumah Sakit Khusus Ibu dan Anak Kota Bandung hampir sebagian besar adalah tenaga perawat. Diketahui pula rata-rata umur responden yaitu 32 tahun dan rata-rata masa kerja yaitu 9 tahun.

Pada tabel 2 menunjukan perbandingan pengetahuan pengelolaan limbah medis padat antara dokter dan non dokter. Didapatkan 13 dokter $(68,4 \%)$ yang menjawab dengan benar mengenai daur ulang (recycle) yang termasuk kedalam upaya untuk mengurangi limbah yang dihasilkan sedangkan non dokter hanya 27 responden $(19,3 \%)$ yang mampu menjawab dengan benar. Pada pertanyaan mengenai limbah kimia yang harus dibuang pada kontainer berwarna coklat, 18 dokter $(94,7 \%)$ dan 123 non dokter $(87,9 \%)$ menjawab dengan benar pertanyaan tersebut. Sedangkan untuk pertanyaan mengenai pengelolaan limbah umum yang dibuang pada kantong plastik berwarna putih, terdapat 15 dokter $(78,9 \%)$ dan 91 non dokter $(65 \%)$ yang menjawab dengan benar.

Tabel 1 Karakteristik Responden $(n=159)$

\begin{tabular}{cc}
\hline Karakteristik & Statistik \\
\hline Jenis Kelamin & \\
Perempuan & $86,8 \%$ \\
Laki-laki & $13,2 \%$
\end{tabular}

Umur (tahun)

$\begin{array}{cc}\text { Rerata } \pm \text { Simpang baku } & 32,3 \pm 6,75 \\ \text { Median } \pm \text { IQR (InterQuartile } & 30,0 \pm 8,00 \\ \text { Range) } & \end{array}$

Pekerjaan

$\begin{array}{cc}\text { Dokter } & 11,9 \% \\ \text { Perawat } & 38,4 \% \\ \text { Bidan } & 35,2 \% \\ \text { Farmasi } & 8,2 \% \\ \text { Analis } & 6,3 \%\end{array}$

Masa Kerja (tahun)

\begin{tabular}{cc} 
Rerata \pm Simpang baku & $9,1 \pm 6,21$ \\
Median \pm IQR (InterQuartile & $8,0 \pm 7,00$ \\
Range) & \\
\hline
\end{tabular}


Tabel 2 Perbandingan Pengetahuan terhadap Pengelolaan Limbah Medis Padat Antara Kelompok Dokter dan Non Dokter

\begin{tabular}{|c|c|c|c|c|c|}
\hline \multirow[b]{2}{*}{ Item Pengetahuan } & \multirow{2}{*}{$\begin{array}{l}\text { Frekuensi } \\
\quad \text { Benar }\end{array}$} & \multicolumn{2}{|c|}{ Kelompok } & \multicolumn{2}{|c|}{ Statistik } \\
\hline & & Dokter & $\begin{array}{c}\text { Non } \\
\text { Dokter }\end{array}$ & $x^{2}$ & $\bar{p}$ \\
\hline $\begin{array}{l}\text { Pengelolaan limbah medis padat adalah proses } \\
\text { untuk mengurangi volume, berat dan bahaya } \\
\text { limbah medis padat, mulai tahap pemilahan } \\
\text { sampai pemusnahannya }\end{array}$ & $\begin{array}{c}158 \\
(99,4 \%)\end{array}$ & $\begin{array}{c}19 \\
(100 \%)\end{array}$ & $\begin{array}{l}139 \\
(99,3 \%)\end{array}$ & 0,137 & 0,712 \\
\hline $\begin{array}{l}\text { Daur ulang (recycle) tidak termasuk kedalam } \\
\text { upaya yang dilakukan rumah sakit untuk } \\
\text { mengurangi jumlah limbah yang dihasilkan }\end{array}$ & $\begin{array}{c}40 \\
(25,2 \%)\end{array}$ & $\begin{array}{c}13 \\
(68,4 \%)\end{array}$ & $\begin{array}{c}27 \\
(19,3 \%)\end{array}$ & 21,452 & $<0,001$ \\
\hline $\begin{array}{l}\text { Limbah medis padat yang bersifat infeksius } \\
\text { dibuang kedalam kontainer berwarna kuning }\end{array}$ & $\begin{array}{c}157 \\
(98,7 \%)\end{array}$ & $\begin{array}{c}19 \\
(100 \%)\end{array}$ & $\begin{array}{c}138 \\
(98,6 \%)\end{array}$ & 0,275 & 0,600 \\
\hline $\begin{array}{l}\text { Limbah benda tajam harus dibuang pada kontainer } \\
\text { anti tusuk }\end{array}$ & $\begin{array}{c}159 \\
(100 \%)\end{array}$ & $\begin{array}{c}19 \\
(100 \%)\end{array}$ & $\begin{array}{c}140 \\
(100 \%)\end{array}$ & $>0,05$ & $>0,05$ \\
\hline $\begin{array}{l}\text { Limbah kimia dibuang pada kontainer berwarna } \\
\text { coklat }\end{array}$ & $\begin{array}{c}141 \\
(88,7 \%)\end{array}$ & $\begin{array}{c}18 \\
(94,7 \%)\end{array}$ & $\begin{array}{c}123 \\
(87,9 \%)\end{array}$ & 0,789 & 0,374 \\
\hline $\begin{array}{l}\text { Limbah medis padat harus segera dipindahkan } \\
\text { apabila kontainer sudah } 3 / 4 \text { penuh }\end{array}$ & $\begin{array}{c}156 \\
(98,1 \%)\end{array}$ & $\begin{array}{c}19 \\
(100 \%)\end{array}$ & $\begin{array}{c}137 \\
(97,9 \%)\end{array}$ & 0,415 & 0,519 \\
\hline $\begin{array}{l}\text { Limbah medis padat yang berjenis limbah umum } \\
\text { seperti kertas dan plastik dibuang pada kantong } \\
\text { plastik berwarna putih }\end{array}$ & $\begin{array}{c}106 \\
(66,7 \%)\end{array}$ & $\begin{array}{c}15 \\
(78,9 \%)\end{array}$ & $\begin{array}{c}91 \\
(65 \%)\end{array}$ & 1,464 & 0,226 \\
\hline $\begin{array}{l}\text { Limbah medis padat berjenis limbah farmasi harus } \\
\text { dibuang pada kontainer berwarna coklat dengan } \\
\text { label berbahaya }\end{array}$ & $\begin{array}{c}134 \\
(84,3 \%)\end{array}$ & $\begin{array}{c}19 \\
(100 \%)\end{array}$ & $\begin{array}{c}115 \\
(82,1 \%)\end{array}$ & 4,026 & 0.045 \\
\hline $\begin{array}{l}\text { Limbah medis padat yang berjenis limbah } \\
\text { patologik dibuang pada kontainer berwarna } \\
\text { kuning dengan simbol "biohazard" }\end{array}$ & $\begin{array}{c}145 \\
(91,2 \%)\end{array}$ & $\begin{array}{c}19 \\
(100 \%)\end{array}$ & $\begin{array}{c}126 \\
(90 \%)\end{array}$ & 2,083 & 0,149 \\
\hline
\end{tabular}

Berdasarkan hasil analisis statistika diketahui bahwa dari 9 pertanyaan mengenai pengetahuan pengelolaan limbah medis padat terdapat 2 pertanyaan yang memiliki hubungan antara pengetahuan pengelolaan limbah medis padat dengan tenaga kesehatan dokter dan non dokter yaitu pada pertanyaan nomor 2 dengan nilai $p$ yaitu $<0,001$ dan pertanyaan nomor 8 dengan nilai p yaitu 0,045 .

Berdasarkan penelitian yang dilakukan untuk mengetahui sikap tenaga kesehatan kelompok dokter dan non dokter, terdapat 19 dokter yang menjadi responden, hampir seluruh dokter yaitu 18 responden $(94,7 \%)$ menjawab pertanyaan sikap tertentu dengan seharusnya dan satu pertanyaan yang 15 dokter $(78,9 \%)$ jawab dengan seharusnya, sedangkan untuk non dokter banyak yang menjawab setiap pertanyaan tidak sesuai dengan sikap yang seharusnya.

Dari hasil uji statistik didapatkan bahwa semua pertanyaan mengenai sikap tenaga kesehatan terhadap pengelolaan limbah medis padat memiliki hubungan antara sikap pengelolaan limbah medis padat dengan tenaga kesehatan dokter dan non dokter.
Berdasarkan tabel 4, didapatkan bahwa sebanyak $84,2 \%$ dokter dan $52,9 \%$ non dokter memliki pengetahuan yang baik, $15,8 \%$ dokter dan $27,1 \%$ non dokter memiliki pengetahuan sedang dan sisanya yaitu $20 \%$ non dokter memiliki pengetahuan yang kurang terhadap pengelolaan limbah medis padat.

Penilaian terhadap sikap, terdapat $94,7 \%$ dokter dan $80,7 \%$ non dokter memiliki sikap yang baik terhadap pengelolaan limbah medis padat dan sisanya yaitu 5,3\% dokter dan 19,3\% non dokter memiliki sikap kurang baik terhadap pengelolaan limbah medis padat.

Hasil statistik menunjukan bahwa terdapat hubungan antara pengetahuan tenaga kesehatan terhadap pengelolaan limbah medis padat dengan tenaga kesehatan medis dan non-medis yang menunjukan nilai $\mathrm{p}$ adalah $<0,001$ ), sedangkan untuk sikap tenaga kesehatan terhadap pegelolaan limbah medis padat tidak memiliki hubungan yang bermakna dengan tenaga kesehatan medis dan non-medis dengan hasil $\mathrm{p}$ yaitu 0,300 . 
Tabel 3 Perbandingan Sikap terhadap Pengelolaan Limbah Medis Padat Antara Kelompok Dokter dan Non Dokter

\begin{tabular}{|c|c|c|c|c|c|}
\hline \multirow[b]{2}{*}{ Item Sikap } & \multirow{2}{*}{$\begin{array}{l}\text { Total Sikap } \\
\text { Positif }\end{array}$} & \multicolumn{2}{|c|}{ Kelompok } & \multicolumn{2}{|c|}{ Statistik } \\
\hline & & Dokter & $\begin{array}{c}\text { Non } \\
\text { Dokter }\end{array}$ & $x^{2}$ & $\bar{p}$ \\
\hline $\begin{array}{l}\text { Limbah medis padat dikumpulkan terlebih } \\
\text { dahulu hingga penuh lalu harus segera diangkut }\end{array}$ & $\begin{array}{c}119 \\
(74,8 \%)\end{array}$ & $\begin{array}{c}15 \\
(78,9 \%)\end{array}$ & $\begin{array}{c}104 \\
(74,3 \%)\end{array}$ & 10,583 & 0,032 \\
\hline $\begin{array}{l}\text { Limbah medis padat tidak dipisahkan } \\
\text { berdasarkan klasifikasi karena semua limbah } \\
\text { medis padat adalah sama dan akan dihancurkan } \\
\text { atau dibuang juga }\end{array}$ & $\begin{array}{c}142 \\
(89,3 \%)\end{array}$ & $\begin{array}{c}18 \\
(94,7 \%)\end{array}$ & $\begin{array}{c}124 \\
(88,6 \%)\end{array}$ & 12,888 & 0,012 \\
\hline $\begin{array}{l}\text { Semua limbah medis padat adalah sama, maka } \\
\text { dengan adanya kontainer untuk membuang } \\
\text { limbah medis padat berdasarkan klasifikasinya } \\
\text { hanya akan membuang uang saja }\end{array}$ & $\begin{array}{c}144 \\
(90,6 \%)\end{array}$ & $\begin{array}{c}19 \\
(100 \%)\end{array}$ & $\begin{array}{c}125 \\
(89,3 \%)\end{array}$ & 16,082 & 0,003 \\
\hline $\begin{array}{l}\text { Buang limbah medis padat pada satu tempat } \\
\text { saja karena ada petugas lain yang akan } \\
\text { mengelola limbah tersebut, sehingga tidak } \\
\text { membuang waktu }\end{array}$ & $\begin{array}{c}136 \\
(85,5 \%)\end{array}$ & $\begin{array}{c}19 \\
(100 \%)\end{array}$ & $\begin{array}{c}117 \\
(83,6 \%)\end{array}$ & $>16,651$ & 0,002 \\
\hline $\begin{array}{l}\text { Limbah medis padat dibuang dalam satu tempat } \\
\text { dahulu agar tidak membuang waktu, lalu jika } \\
\text { sudah penuh maka dipisahkan berdasarkan } \\
\text { klasifikasinya }\end{array}$ & $\begin{array}{c}134 \\
(84,3 \%)\end{array}$ & $\begin{array}{c}18 \\
(94,7 \%)\end{array}$ & $\begin{array}{c}116 \\
(82,9 \%)\end{array}$ & 10,725 & 0,030 \\
\hline
\end{tabular}

Tabel 4 Gambaran Pengetahuan dan Sikap Antara Kelompok Dokter dan Non dokter

\begin{tabular}{|c|c|c|c|c|c|c|}
\hline \multirow[b]{2}{*}{ Item } & & & \multicolumn{2}{|c|}{ Kelompok } & \multicolumn{2}{|c|}{ Statistik } \\
\hline & & & Dokter & Non Dokter & $x^{2}$ & $\mathbf{P}$ \\
\hline \multirow[t]{3}{*}{ Pengetahuan } & $\begin{array}{l}\text { Baik } \\
(>85)\end{array}$ & $\begin{array}{c}90 \\
(56,6 \%)\end{array}$ & $\begin{array}{c}16 \\
(84,2 \%)\end{array}$ & $\begin{array}{c}74 \\
(52,9 \%)\end{array}$ & 26,865 & $<0,001$ \\
\hline & $\begin{array}{l}\text { Sedang } \\
(71-85 \%)\end{array}$ & $\begin{array}{c}41 \\
(25,8 \%)\end{array}$ & $\begin{array}{c}3 \\
(15,8 \%)\end{array}$ & $\begin{array}{c}38 \\
(27,1)\end{array}$ & & \\
\hline & $\begin{array}{l}\text { Kurang } \\
(\leq 70 \%)\end{array}$ & $\begin{array}{c}28 \\
(17,6 \%)\end{array}$ & $\begin{array}{c}0 \\
(0 \%)\end{array}$ & $\begin{array}{c}28 \\
(20 \%)\end{array}$ & & \\
\hline \multirow[t]{2}{*}{ Sikap } & $\begin{array}{l}\text { Baik } \\
(>70 \%)\end{array}$ & $\begin{array}{c}131 \\
(82,4 \%)\end{array}$ & $\begin{array}{c}18 \\
(94,7 \%)\end{array}$ & $\begin{array}{c}113 \\
(80,7 \%)\end{array}$ & 17,330 & 0,300 \\
\hline & $\begin{array}{c}\text { K u r a n g } \\
\text { Baik } \\
(\leq 70 \%)\end{array}$ & $\begin{array}{c}28 \\
(17,6 \%)\end{array}$ & $\begin{array}{c}1 \\
(5,3 \%)\end{array}$ & $\begin{array}{c}27 \\
(19,3 \%)\end{array}$ & & \\
\hline
\end{tabular}

\section{Pembahasan}

Tenaga kesehatan sebagai penghasil limbah medis padat memiliki risiko yang besar terhadap kecelakaan dan penyebaran penyakit sehingga sebagai orang pertama yang berkontak langsung dengan limbah medis dan penghasil limbah medis seharusnya memiliki pengetahuan dan sikap yang baik tentang pengelolaan limbah medis padat agar menjadi pencegah dari terjadinya risiko yang memungkinkan terjadi akibat limbah medis padat seperti tertusuk jarum suntik yang telah terkontaminasi HIV atau hepatitis, sehingga HIV dan hepatitis tersebut dapat menyebar. Penelitian yang telah dilakukan di Pekanbaru sesuai dengan penelitian ini, bahwa risiko pekerjaan tenaga kesehatan seperti tertusuknya jarum bekas/ tidak steril menjadi faktor risiko kedua tertinggi terhadap penularan penyakit hepatitis B pada tenaga kesehatan. ${ }^{4}$

Hasil penelitian ini didapatkan bahwa dokter memiliki pengetahuan pengelolaan limbah medis padat yang lebih baik $(84,2 \%)$ dibandingkan non dokter $(52,9 \%)$ dan terdapat hubungan antara pengetahuan pengelolaan limbah medis padat dengan tenaga kesehatan 
antara dokter dan non dokter $(\mathrm{p}<0,001)$. Hasil ini sesuai dengan penelitian yang dilakukan oleh S.A. Hakim, A. Mohsen dan I. Bakr di Ain Shams University Hospitals, Kairo, Mesir yang menjelaskan bahwa dokter $(68,3 \%)$ memiliki skor pengetahuan lebih tinggi dibandingkan non dokter yaitu perawat $(60,9 \%)$ dan terdapat hubungan antara pengetahuan pengelolaan limbah medis dengan tenaga kesehatan dokter dan non dokter dengan nilai $\mathrm{p}<0,001 .{ }^{8}$ Penelitian ini juga mendapatkan bahwa dokter (94,7\%) memiliki sikap yang baik terhadap pengelolaan limbah medis padat dibandingkan non dokter $(80,7 \%)$. Berbeda dengan pengetahuan, disini tidak terdapat hubungan antara sikap terhadap pengelolaan limbah medis padat dengan tenaga kesehatan dokter dan non dokter yang dibuktikan dengan nilai $\mathrm{p} 0,300$. Hasil penelitian ini pun sesuai dengan penelitian yang dilakukan oleh S.A. Hakim, A. Mohsen dan I. Bakr di Ain Shams University Hospitals, Kairo, Mesir yang menjelaskan bahwa dokter $(56,4 \%)$ memiliki sikap yang lebih baik terhadap pengelolaan limbah medis dibandingkan non dokter yaitu perawat (49\%). Hasil penelitian lain menunjukan bahwa tidak terdapat hubungan antara sikap terhadap pengelolaan limbah medis dengan tenaga kesehatan dokter dan non dokter dengan nilai $p$ yaitu $0,142 .{ }^{8}$ Berdasarkan pernyataan pada buku promosi kesehatan dan ilmu perilaku yang ditulis oleh Notoatmodjo bahwa terdapat faktor-faktor yang mempengaruhi pengetahuan seseorang yaitu pendidikan, media masa/sumber informasi, sosial budaya dan ekonomi, lingkungan dan pengalaman. ${ }^{9}$ Rendahnya pengetahuan tenaga kesehatan terhadap pengelolaan limbah medis pada penelitian ini mungkin dipengaruhi oleh kelima faktor tersebut dan begitu pula dengan rendahnya sikap tenaga kesehatan terhadap pengelolaan limbah medis padat.

Keterbatasan dalam penelitian ini tidak diikutsertakannya variabel lain yang mempengaruhi pengetahuan dan sikap tenaga kesehatan terhadap pengelolaan limbah medis padat. Hal ini dikarenakan keterbatasan waktu dan jumlah responden yang sedikit sehingga sulit untuk menganalisis variabel lain. Selain itu, peneliti tidak mempertimbangkan aspek pendidikan responden dan lamanya kerja yang mungkin dapat berpengaruh dalam pengisian kuesioner.

Hasil penelitian menunjukan bahwa tenaga kesehatan memiliki sikap yang baik dan pengetahuan yang kurang terhadap pengelolaan limbah medis padat, dokter mempunyai pengetahuan dan sikap pengelolaan limbah medis padat lebih baik dibandingkan non dokter, terdapat hubungan antara pengetahuan pengelolaan limbah medis padat dengan dokter dan non dokter, dan tidak terdapat hubungan antara sikap pengelolaan limbah medis padat dengan dokter dan non dokter. Hasil penelitian ini dapat menjadi pertimbangan untuk dilakukannya pelatihan yang bertujuan meningkatkan pengetahuan dan sikap para tenaga kesehatan dalam pengelolaan limbah medis khususnya limbah medis padat agar dapat mengurangi risiko yang mungkin terjadi dari kecelakaan kerja atau infeksi nosokomial.

\section{Daftar Pustaka}

1. World Health Organization. Safe management of wastes from health-care activities. Switzerland. 2014.

2. Sutarjo Untung Suseno, Yudianto, Didik Budijanto, Boga Hardhana, Titi Aryati Soenardi, dkk. Profil Kesehatan Indonesia Tahun 2014. Jakarta: Kementerian Kesehatan Republik Indonesia. 2015.

3. Ozder Aclan, Bahri Teker, Hasan Huseyin Eker, Selma Altindis, Merve Kocaakman, dkk. Medical waste management training for healthcare managers - a necessity? Journal of Environmental Health Science and Engineering. 2013;11(1):20.

4. Amtarina Rina, Arfianti, Andi Zainal, Fifia Chandra. Faktor Risiko Hepatitis B pada Tenaga Kesehatan kota Pekanbaru. Bandung Medical Journal. 2009;41.

5. Sarker Mohammad Abul Bashar, M HarunOr-Rashid, Tomoya Hirosawa, M Shaheen Bin Abdul Hai , M Ruhul Furkan Siddique, dkk. Evaluation of Knowledge, Practices, and Possible Barriers among Healthcare Providers regarding Medical Waste Management in Dhaka, Bangladesh. Medical Science Monitor. 2014;20:2590-7.

6. Pujimukti Niki. Hubungan Antara Pengetahuan, Sikap dan Perilaku Petugas Terhadap Pengelolaan Sampah Medis PuskesmasdiKabupatenJember.Jember.2012.

7. Sudiharti, Solikhah. Hubungan Pengetahuan dan Sikap dengan Perilaku Perawat dalam Pembuangan Sampah Medis di Rumah Sakit PKU Muhammadiyah Yogyakarta. Yogyakarta: Jurnal Kesehatan Masyarakat Universitas Ahmad Dahlan. 2012;6.

8. Hakim SA, A Mohsen, I Bakr. Knowledge, attitudes and practices of health-care personnel towards waste disposal management at Ain Shams University Hospitals, Cairo. Eastern Mediterranean Health Journal. 2014;20(5):347-54.

9. Notoatmodjo Soekidjo. Promosi Kesehatan \& Ilmu Perilaku. Jakarta: Rineka Cipta. 2007. 